\title{
Calf birth weight, gestation length, calving ease, and neonatal calf mortality in Holstein, Jersey, and crossbred cows in a pasture system
}

\author{
K. Dhakal, ${ }^{* 1}$ C. Maltecca, ${ }^{\star}$ J. P. Cassady, ${ }^{*}$ G. Baloche,$\dagger$ C. M. Williams, $\ddagger$ and S. P. Washburn* \\ *Department of Animal Science, North Carolina State University, Raleigh 27695 \\ †French National Institute of Agricultural Research, 31450 Toulouse, France \\ ¥Department of Molecular Biomedical Sciences, North Carolina State University, Raleigh 27695
}

\section{ABSTRACT}

Holstein (HH), Jersey (JJ), and crosses of these breeds were mated to $\mathrm{HH}$ or JJ bulls to form purebreds, reciprocal crosses, backcrosses, and other crosses in a rotational mating system. The herd was located at the Center for Environmental Farming Systems in Goldsboro, North Carolina. Data for calf birth weight $(\mathrm{CBW})$, calving ease ( 0 for unassisted, $\mathrm{n}=1,135$, and 1 for assisted, $\mathrm{n}=96$ ), and neonatal calf mortality ( 0 for alive, $\mathrm{n}=1,150$, and 1 for abortions recorded after mid-gestation, stillborn, and dead within $48 \mathrm{~h}$, $\mathrm{n}=81)$ of calves $(\mathrm{n}=1,231)$ were recorded over 9 calving seasons from 2003 through 2011. Gestation length (GL) was calculated as the number of days from last insemination to calving. Linear mixed models for CBW and GL included fixed effects of sex, parity (first vs. later parities), twin status, and 6 genetic groups: $\mathrm{HH}$, JJ, reciprocal $\mathrm{F}_{1}$ crosses (HJ, JH), crosses $>50 \%$ Holsteins (HX) and crosses $>50 \%$ Jerseys (JX), where sire breed is listed first. The CBW model also included GL as a covariate. Logistic regression for calving ease and neonatal calf mortality included fixed effects of sex, parity, and genetic group. Genetic groups were replaced by linear regression using percentage of $\mathrm{HH}$ genes as coefficients on the above models and included as covariates to determine various genetic effects. Year and dam were included as random effects in all models. Female calves $(27.57 \pm 0.54 \mathrm{~kg})$, twins $(26.39 \pm 1.0 \mathrm{~kg})$, and calves born to first-parity cows $(27.67 \pm 0.56 \mathrm{~kg})$ had lower CBW than respective male calves $(29.53 \pm 0.53$ $\mathrm{kg})$, single births $(30.71 \pm 0.19 \mathrm{~kg})$, or calves born to multiparous cows $(29.43 \pm 0.52 \mathrm{~kg})$. Differences in genetic groups were observed for CBW and GL. Increased $\mathrm{HH}$ percentage in the calf increased $\mathrm{CBW}(+9.3 \pm 0.57$ $\mathrm{kg}$ for $\mathrm{HH}$ vs. JJ calves), and increased $\mathrm{HH}$ percentage in the dams increased CBW $(+1.71 \pm 0.53 \mathrm{~kg}$ for calves from $\mathrm{HH}$ dams vs. JJ dams); JH calves weighed 1.33 $\mathrm{kg}$ more than reciprocal HJ calves. Shorter GL was

Received June 7, 2012.

Accepted September 10, 2012.

${ }^{1}$ Corresponding author: kdhakal@ncsu.edu observed for twin births $(272.6 \pm 1.1 \mathrm{~d})$, female calves $(273.9 \pm 0.6 \mathrm{~d})$, and for first-parity dams $(273.8 \pm 0.6$ d). Direct genetic effects of $\mathrm{HH}$ alleles shortened GL $(-3.5 \pm 0.7 \mathrm{~d})$, whereas maternal $\mathrm{HH}$ alleles increased GL $(2.7 \pm 0.6 \mathrm{~d})$. Female calves had lower odds ratio $(0.32$, confidence interval $=0.10-0.99)$ for neonatal calf mortality in second and later parities than did male calves. Maternal heterosis in crossbred primiparous dams was associated with reduced calf mortality.

Key words: crossbreeding, genetic group, Holstein, Jersey

\section{INTRODUCTION}

Calving ease and neonatal calf mortality are economically important traits in the dairy business. Calving is a stressful event for the cow. The amount of stress is often affected by high calf birth weight $(\mathbf{C B W})$, calving difficulty, and calf mortality (Olson et al., 2009). Calving difficulty has been associated with reduced survival of both cow and calf, as well as lower production, fertility, and longevity for the cow. Calving difficulty can lead to increased rates of neonatal calf mortality, lower milk production, and overall reduced health of cows (Heins et al., 2006a). Stillbirth, abortion, and death of calves after parturition are an immediate economic loss. In addition, loss of female calves increases the number of pregnant females needed to produce replacement females to maintain cow numbers in a herd. For births that require assistance during calving, additional cost estimates range from $\$ 96.48$ to $\$ 397.61$, depending on the type of assistance needed (Dematawewa and Berger, 1997).

Holsteins have dominated the dairy industry in the United States due to their high milk production. Jerseys are the second most popular cow breed in the United States and account for $7 \%$ of the US dairy population. Over the past several decades, average milk production per cow has increased. In contrast, health and fertility traits have declined (Bjelland et al., 2011). Numerous studies have evaluated crossbreeding Holsteins with other breeds to improve production, fertility, surviv- 
ability, and calving ease (Heins et al., 2006a, b, 2008; Sørensen et al., 2008; Prendiville et al., 2010). Interest in crossbreeding has grown over the past decade among both dairy producers and researchers especially to improve calving ease (Weigel and Barlass, 2003; Heins et al., 2006b). Many studies have shown benefits in reducing calving difficulties in a crossbreeding system with various breeds (Touchberry, 1992; Heins et al., 2006a,b; Maltecca et al., 2006).

Olson et al. (2009) reported a significant decrease in calving difficulty for Jersey-sired crossbred calves compared with Holstein calves. Heins et al. (2003) found that Jersey-sired calves out of Holstein dams had less calving difficulty than pure Holstein. Heins et al. (2006a) also found that crossbred dams had less calving difficulty than purebred dams. Sørensen et al. (2008) reported unfavorable heterosis for direct effects in calving ease and neonatal calf mortality in heifers, and found favorable heterosis for maternal effects for both calving ease and neonatal calf mortality. Olson et al. (2009) reported unfavorable direct genetic effects in calving ease and found favorable maternal genetic effects for both calving ease and neonatal calf mortality.

The objective of this study was to evaluate differences in CBW, gestation length (GL), calving ease, and neonatal calf mortality among purebred Holstein, Jersey, their reciprocal crosses, backcrosses, and other crosses in a planned rotational mating program in a pasture-based production system.

\section{MATERIALS AND METHODS}

\section{Experimental Design}

A pasture-based dairy crossbreeding system using purebred Holstein $(\mathbf{H H})$ and Jersey $(\mathbf{J J})$ cattle was established at the Center for Environment Farming Systems (CEFS; Goldsboro, NC). The crossbreeding system was designed so that each purebred cow or heifer was inseminated using semen from the same breed one year or from the opposite breed the next year based on odd and even eartag numbers. The same alternating breeding scheme was used for $\mathrm{F}_{1}$ heifers and cows $(\mathbf{J H}$ and $\mathbf{H J}$, with sire breed first) such that any $\mathrm{F}_{1}$ cow would have a calf that was $75 \% \mathrm{HH}$ one year and another calf that was $75 \%$ JJ the next year or vice versa. For cows and heifers that were $>50 \%$ of one breed (e.g., $75,62.5$, or $68.75 \%$ ), all matings were planned to be to the opposite breed, so that $75 \%$ of one breed was theoretically the highest percentage cross. In practice, for $1.87 \%$ of cases, a mating was inadvertently made to the same breed as the sire, resulting in different percentages of crossbred offspring than planned. Six genetic groups were formed by using this crossbreeding system: purebred HH, purebred JJ, reciprocal $\mathrm{F}_{1}$ crosses (HJ, $\mathrm{JH})$, crosses $>50 \% \mathrm{HH}(\mathbf{H X}$; average $=69.25 \% \mathrm{HH})$, and crosses $>50 \% \mathrm{JJ}(\mathbf{J X}$; average $=29.0 \% \mathrm{HH})$. It should be noted that when mating virgin heifers of any breed with $\mathrm{HH}$ sires, calving ease sires were used with predicted difficult births at or below $7 \%$ at the time semen was purchased. This restriction was not in effect for use of $\mathrm{HH}$ sires for breeding lactating cows. Semen from $62 \mathrm{HH}$ sires and 22 JJ sires was used for breeding, which produced 632 calves from $\mathrm{HH}$ sires and 599 calves from JJ sires. Approximately $40 \%$ of the dams had 1 calving observation ( $18 \%$ of total observations), whereas $60 \%$ of the cows calved from 2 to 9 times $(82 \%$ of total observations) during the study.

\section{Recording of Data}

Data for CBW, calving ease, and neonatal calf mortality were recorded over 9 calving seasons from June 2003 through December 2011. Calf birth weights were recorded shortly after calving. Calving ease was measured on a scale from 1 to 5 , where $1=$ no assistance, $2=$ slight problem and required some assistance, $3=$ required moderate assistance, $4=$ required considerable force, and $5=$ extreme difficulty. The distributions of calving ease score were as follows: $1(\mathrm{n}=1,135), 2$ $(\mathrm{n}=44), 3(\mathrm{n}=26), 4(\mathrm{n}=19)$, and $5(\mathrm{n}=7)$. Calving ease scores of 1 were coded as unassisted (0) and calving scores from 2 to 5 were coded as assisted (1) because of the limited number of observations in individual categories. Neonatal calf mortality was coded as 0 for the calf born alive and surviving past $48 \mathrm{~h}$, and 1 for abortions recorded after mid-gestation, stillborn, or dead within $48 \mathrm{~h}$ of calving. Gestation length was calculated as the days from date of last insemination to subsequent date of calving. Gestation length records for 12 cows were removed because they were greater than \pm 3 standard deviations (where $1 \mathrm{SD}$ was $6 \mathrm{~d}$ ) from the mean of $277 \mathrm{~d}$. The data set included 1,231 total calvings with 190, 329, 113, 139, 331, and 129 births of HH, HX, HJ, JH, JX, and JJ calves, respectively (Table 1). Note that $9.8 \%(\mathrm{n}=121)$ of the calves $(\mathrm{HH}, \mathrm{HJ}, \mathrm{JH}$, and JJ from planned matings from 2002 to 2006) in this study were included in the 3-state study of Olson et al. (2009) but are also included in the present study to allow for more robust contemporary comparisons among various breed groups within the pasture-based system.

\section{Statistical Analyses}

Data were analyzed using linear mixed model in SAS (version 9.2, 2008; SAS Institute Inc., Cary, NC). The model used for CBW was 
Table 1. Distributions for calving ease, neonatal calf mortality, sex, and twin status, and means and ranges for calf birth weight and gestation length, for primiparous and multiparous cows in 6 genetic groups ${ }^{1}$

\begin{tabular}{|c|c|c|c|c|c|c|c|c|c|c|c|c|}
\hline \multirow[b]{2}{*}{ Trait } & \multicolumn{2}{|c|}{ HH $(\mathrm{n}=190)$} & \multicolumn{2}{|c|}{$\mathrm{HX}(\mathrm{n}=329)$} & \multicolumn{2}{|c|}{ HJ (n = 113) } & \multicolumn{2}{|c|}{$\mathrm{JH}(\mathrm{n}=139)$} & \multicolumn{2}{|c|}{ JX (n = 331) } & \multicolumn{2}{|c|}{$\mathrm{JJ}(\mathrm{n}=129)$} \\
\hline & Primi & Multi & Primi & Multi & Primi & Multi & Primi & Multi & Primi & Multi & Primi & Multi \\
\hline \multicolumn{13}{|l|}{ Calving ease } \\
\hline Assisted $^{2}(\%)$ & 21.6 & 7.2 & 12.9 & 7.9 & 8.8 & 3.8 & 8.6 & 4.8 & 8.3 & 5.6 & 7.5 & 3.4 \\
\hline No. of observations & 51 & 139 & 139 & 190 & 34 & 79 & 35 & 104 & 133 & 198 & 40 & 89 \\
\hline \multicolumn{13}{|l|}{ Mortality } \\
\hline $\operatorname{Dead}^{3}(\%)$ & 15.7 & 12.9 & 5.0 & 2.6 & 11.8 & 0.0 & 17.1 & 4.8 & 7.5 & 4.0 & 12.5 & 5.6 \\
\hline No. of observations & 51 & 139 & 139 & 190 & 34 & 79 & 35 & 104 & 133 & 198 & 40 & 89 \\
\hline \multicolumn{13}{|l|}{ Sex } \\
\hline Male & 26 & 65 & 60 & 95 & 16 & 43 & 19 & 55 & 65 & 96 & 17 & 47 \\
\hline Female & 19 & 61 & 73 & 91 & 17 & 36 & 13 & 48 & 59 & 97 & 21 & 41 \\
\hline \multicolumn{13}{|l|}{ Twin status } \\
\hline Single & 49 & 127 & 137 & 186 & 34 & 79 & 35 & 98 & 131 & 192 & 38 & 87 \\
\hline Twin & 1 & 6 & 1 & 2 & 0 & 0 & 0 & 3 & 1 & 3 & 1 & 1 \\
\hline \multicolumn{13}{|l|}{ Birth weight (kg) } \\
\hline Mean & 34.0 & 36.6 & 31.0 & 33.5 & 29.6 & 31.1 & 30.8 & 32.9 & 28.5 & 29.4 & 23.7 & 25.0 \\
\hline Minimum & 18.6 & 17.5 & 17.2 & 20.0 & 22.7 & 14.7 & 19.5 & 21.1 & 17.5 & 16.6 & 15.4 & 14.1 \\
\hline Maximum & 42.9 & 50.4 & 44.5 & 51.7 & 40.6 & 40.8 & 41.7 & 45.1 & 39.7 & 53.5 & 37.0 & 35.2 \\
\hline \multicolumn{13}{|l|}{ Gestation length (d) } \\
\hline Mean & 276 & 276 & 274 & 276 & 276 & 276 & 279 & 279 & 276 & 278 & 275 & 278 \\
\hline Minimum & 266 & 259 & 263 & 260 & 267 & 263 & 268 & 260 & 259 & 264 & 263 & 260 \\
\hline Maximum & 291 & 294 & 290 & 295 & 293 & 284 & 291 & 295 & 289 & 295 & 287 & 295 \\
\hline
\end{tabular}

${ }^{1}$ Breed of sire listed first: $\mathrm{H}=$ Holstein, $\mathrm{J}=$ Jersey, $\mathrm{X}=$ crossbreds (dams). Primi = primiparous; Multi = multiparous.

${ }^{2}$ Percentage of births requiring assistance; calving ease scores of $2,3,4$, and 5 as a percentage of total observations in each subgroup.

${ }^{3}$ Percentage of calves born dead or died within $48 \mathrm{~h}$ as a percentage of total observations in each subgroup. 
Table 2. Genetic expectations for each combination of Holstein $(\mathrm{H})$ and Jersey $(\mathrm{J})$ breeds in the experiment

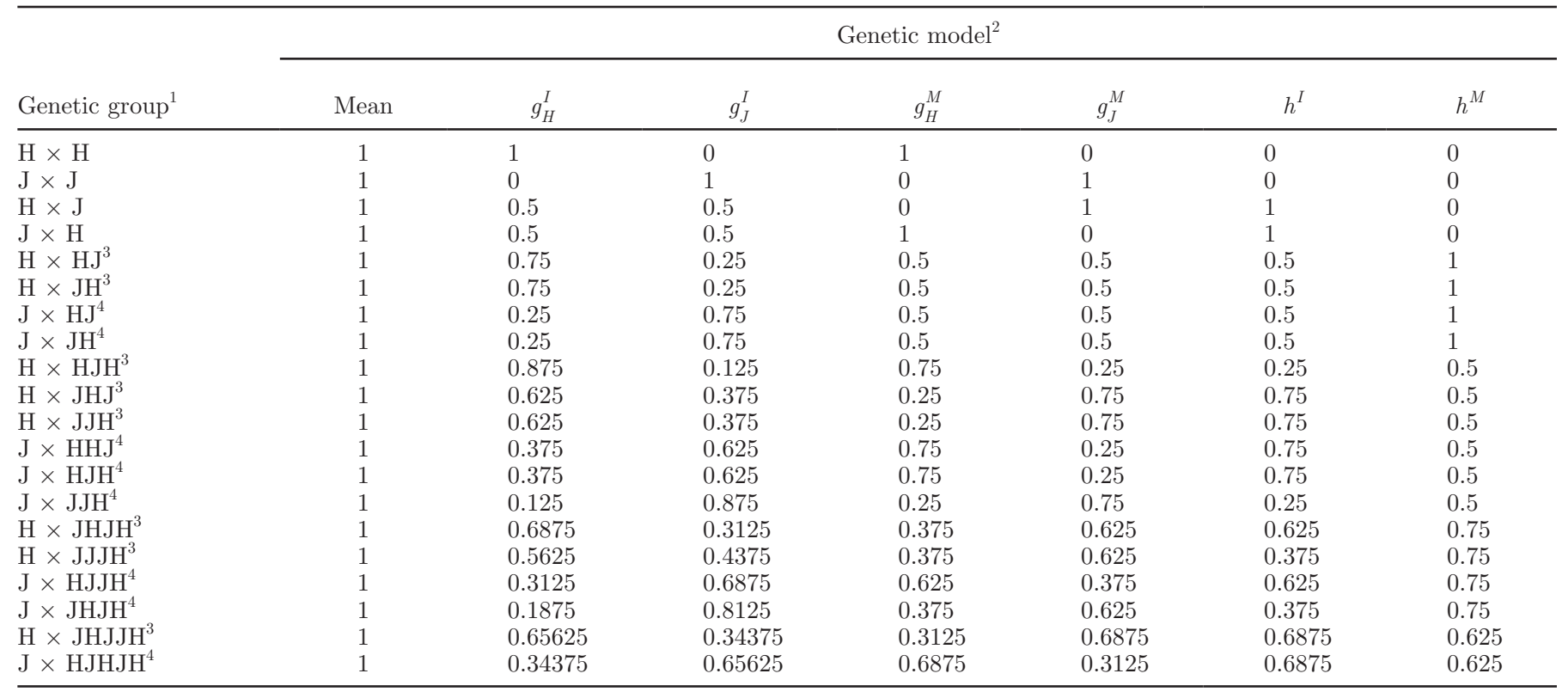

${ }^{1}$ The first letter indicates breed of sire and the second letter indicates breed of dam; $\mathrm{H}=$ Holstein, $\mathrm{J}=$ Jersey.

${ }^{2} g_{i}^{I}$ and $g_{i}^{M}$ indicate direct and maternal breed effects, respectively, where subscript $i$ represents a breed (H or J) associated with the effect; $h^{I}$ and $h^{M}$ are direct and maternal heterosis effects, respectively.

${ }^{3}$ Pooled as HX genetic groups. $\mathrm{X}=$ crossbred.

${ }^{4}$ Pooled as JX genetic groups.

$$
\mathbf{y}=\mathbf{X b}+\mathbf{Z u}+\mathbf{e}
$$

where $\mathbf{y}$ was the observation for $\mathrm{CBW}$; $\mathbf{b}$ was solution vector for fixed effects, which included genetic group (HH, HX, HJ, JH, JX, or JJ), twin status (single or twin), parity of the dam (primiparous or multiparous), sex of the calf (male or female), and GL as covariate; $\mathbf{u}$ was the solution vector for random year and dam effects; $\mathbf{X}$ and $\mathbf{Z}$ were incidence matrices for fixed and random effects; and e was the residual vector. Normality and independence were assumed for the random effect of year and dam.

The model for GL was similar to the CBW model. Interactions between sex, parity, and animal genetic groups were included in the full models. Models were later simplified by removal of interactions that were not significant. Direct and maternal genetic effects and direct and maternal heterosis on CBW and GL were determined in a separate analysis, where genetic groups were replaced by linear regression on heterosis coefficients (Robison et al., 1981) and used as covariates in the above models. The coefficients for the genetic groups (Table 2) were therefore partitioned into percentage $\mathrm{HH}$ alleles in the calf (direct genetic effects), percentage HH alleles in the dam (maternal genetic effects), percentage heterosis in the calf (direct heterosis), and percentage heterosis in the dam (maternal heterosis).

Logistic regression models were used to account for the binary nature of calving ease and neonatal calf mortality data. Data were analyzed separately for first and later parities. The models for calving ease and mortality were

$$
\eta=\mathbf{X b}+\mathbf{Z u}+\mathbf{e}
$$

where $\eta$ was the vector of the logits of the observed events; $\mathbf{b}$ was the solution vector of fixed effects and included sex of the calf and genetic group; and $\mathbf{u}$ included the solutions from the random year and dam effects; $\mathbf{X}$ and $\mathbf{Z}$ were incidence matrices for the fixed and random effects; and $\mathbf{e}$ was the random error term. Interactions between sex and animal genetic groups were not significant and were dropped from original models. In another analysis, direct genetic effects, maternal genetic effects, direct heterosis, and maternal heterosis components replaced genetic group in both the calving ease and mortality models. The relationships of explanatory variables with calving ease and neonatal calf mortality were investigated by odds ratios ( $\mathbf{O R})$, and significant OR were based on a $95 \%$ CI. 
Table 3. Least squares means \pm standard errors for calf birth weight and gestation length

\begin{tabular}{lll}
\hline Item & $\begin{array}{c}\text { Calf birth } \\
\text { weight }(\mathrm{kg})\end{array}$ & $\begin{array}{c}\text { Gestation } \\
\text { length }(\mathrm{d})\end{array}$ \\
\hline Genetic group $^{1}$ & & \\
HH & $33.8 \pm 0.6^{\mathrm{a}}$ & $274.2 \pm 0.7^{\mathrm{b}}$ \\
HX & $30.5 \pm 0.5^{\mathrm{b}}$ & $273.6 \pm 0.7^{\mathrm{b}}$ \\
HJ & $28.4 \pm 0.7^{\mathrm{c} *}$ & $273.6 \pm 0.8^{\mathrm{b}}$ \\
JH & $29.7 \pm 0.7^{\mathrm{b} *}$ & $276.4 \pm 0.8^{\mathrm{a}}$ \\
JX & $26.9 \pm 0.6^{\mathrm{d}}$ & $275.1 \pm 0.7^{\mathrm{a}}$ \\
JJ & $22.1 \pm 0.7^{\mathrm{e}}$ & $275.0 \pm 0.8^{\mathrm{a}}$ \\
Twin status & & \\
Twin & $26.4 \pm 1.0^{\mathrm{b}}$ & $272.6 \pm 1.1^{\mathrm{b}}$ \\
Single & $30.7 \pm 0.2^{\mathrm{a}}$ & $276.6 \pm 0.3^{\mathrm{a}}$ \\
Sex & & \\
Male & $29.5 \pm 0.5^{\mathrm{a}}$ & $275.2 \pm 0.6^{\mathrm{a}}$ \\
Female & $27.6 \pm 0.5^{\mathrm{b}}$ & $273.9 \pm 0.6^{\mathrm{b}}$ \\
Parity & & \\
Primiparous & $27.7 \pm 0.5^{\mathrm{a}}$ & $273.8 \pm 0.6^{\mathrm{b}}$ \\
Multiparous & $29.4 \pm 0.5^{\mathrm{b}}$ & $275.4 \pm 0.6^{\mathrm{a}}$ \\
\hline
\end{tabular}

${ }^{\mathrm{a}-\mathrm{e}}$ Estimates with different superscripts are significantly different, $P<$ $0.01 ;$ * estimates different at $P<0.05$.

${ }^{1}$ Sire breed by dam breed; $\mathrm{H}=$ Holstein; $\mathrm{J}=$ Jersey; $\mathrm{X}=$ crossbreed.

\section{RESULTS AND DISCUSSION}

\section{CBW and $G L$}

Least squares means for CBW and GL are presented in Table 3. Twinning was significant for both CBW and GL $(P<0.01)$. Twins weighed less than single births and had shorter GL. Sex of the calf was significant for CBW and GL $(P<0.01)$ : male calves weighed more than female calves and had longer GL. Parity status of the cows explained significant variation in CBW and GL $(P<0.01)$, and calves from primiparous cows weighed less than calves from multiparous cows, with shorter GL. Gestation length significantly explained variation $(P<0.01)$ for CBW, with an increase of 0.12 $\pm 0.02 \mathrm{~kg}$ of CBW per day of gestation.

Genetic group explained significant variation in CBW and GL. The HH genetic group had significantly greater CBW than the other genetic groups $(P<0.01)$, whereas the JJ genetic group had the lowest CBW. The HX genetic group had higher CBW than either HJ or JX $(P<0.01)$ but was similar to JH. In the current study, JH births were $1.33 \mathrm{~kg}$ more than HJ $(P<0.05)$. In contrast, Olson et al. (2009) reported a difference of $1.18 \mathrm{~kg}$ (not significant) between those reciprocal crosses. Differences of $\mathrm{CBW}$ between purebred $\mathrm{HH}$ calves and reciprocal crosses (HJ and $\mathrm{JH}$ ) were smaller (5.4 kg and $4.1 \mathrm{~kg}$, respectively; $P<0.01$ ) than the 7.9 $\mathrm{kg}(\mathrm{HJ})$ reported by Heins et al. (2003) and the $8.6 \mathrm{~kg}$ (HJ) or $7.4 \mathrm{~kg}(\mathrm{JH})$ reported by Olson et al. (2009). The difference between HH and HX calves was greater $(3.3 \mathrm{~kg} ; P<0.01)$ than the $1.9-\mathrm{kg}$ difference between the $75 \% \mathrm{HH}$ calves and purebred $\mathrm{HH}$ calves reported by Maltecca et al. (2006). A slightly larger difference might be expected because the average percentage Holstein in the HX calves in the current study was $69.25 \%$.

Calves born from primiparous cows weighed $1.8 \mathrm{~kg}$ less than calves born from multiparous cows. In contrast, Johanson and Berger (2003), Olson et al. (2009), and Maltecca et al. (2006) reported differences between multiparous and primiparous cows of 3.5, 3.4, and 3.2 $\mathrm{kg}$, respectively. Male calves weighed $2.0 \mathrm{~kg}$ more than female calves in the current study, whereas Olson et al. (2009) reported a difference of $2.6 \mathrm{~kg}$ and Maltecca et al. (2006) reported a difference of $1.3 \mathrm{~kg}$ between male and female calves.

Gestation length was longer for the JH genetic group than for the HH, HX, and HJ genetic groups. Similarly, GL was shorter for purebred HH (274 d) than for purebred JJ (275 d). In contrast to the current study, Silva et al. (1992) reported that JJ (278 d) had shorter gestation than HH (280 d). Heins et al. (2010) reported that Montbeliarde-sired calves from multiparous $\mathrm{HH}$ dams had significantly longer GL (283.2 d) than HH-sired calves from $\mathrm{HH}$ dams $(278.4 \mathrm{~d})$. The study of Heins et al. (2010) also reported that GL was significantly longer for JJ $\times \mathrm{HH}$ cows bred to Montbeliarde bulls than for pure $\mathrm{HH}$ cows bred to $\mathrm{HH}$ bulls at first calving (280.3 vs. 277.7 d) and second and third calving (282.2 vs. $278.6 \mathrm{~d}$ ). Male calves had longer gestations, by 1.2 d, which is consistent with Silva et al. (1992) and Olson et al. (2009), who reported GL for male calves that were $0.99 \mathrm{~d}$ and $1.1 \mathrm{~d}$ longer, respectively, than those of female calves. In the current study, twins had GL $4 \mathrm{~d}$ shorter than singletons, which is slightly less than the 4.8-d difference reported by Olson et al. (2009).

Analyses for regression on genetic group components for CBW and GL are shown in Table 4. In CBW analysis, the direct genetic effects were significant $(P<$ 0.01 ), and calves that were $100 \% \mathrm{HH}$ were expected to weigh $9.3 \pm 0.6 \mathrm{~kg}$ more than calves that were $100 \%$ JJ. Olson et al. (2009) reported that $100 \% \mathrm{HH}$ calves were expected to weigh $14.3 \pm 2.4 \mathrm{~kg}$ more than $100 \% \mathrm{JJ}$ calves. The maternal genetic effects were significant $(P$ $<0.01$ ), and calves from $100 \% \mathrm{HH}$ cows were expected to weigh $1.7 \pm 0.5 \mathrm{~kg}$ more than calves from $100 \% \mathrm{JJ}$ cows. Direct heterosis $(P=0.08)$ and maternal heterosis $(P=0.98)$ for CBW were not significant.

In the GL regression analysis, direct genetic effects were significant $(P<0.01)$ in that $100 \% \mathrm{HH}$ calves were expected to have GL $3.5 \pm 0.7 \mathrm{~d}$ shorter than $100 \%$ JJ calves. The maternal genetic effects were significant $(P$ $<0.01$ ), and calves from $100 \% \mathrm{HH}$ cows were expected to have GL $2.7 \pm 0.6 \mathrm{~d}$ longer than calves from $100 \% \mathrm{JJ}$ cows. Therefore, the maternal genetic effects $(+2.7 \mathrm{~d})$ nearly offset the direct genetic effects $(-3.5 \mathrm{~d})$. Direct heterosis $(P=0.45)$ and maternal heterosis $(P=0.18)$ for GL were not significant. 
Table 4. Regression on genetic group comparison for calf birth weight and gestation length

\begin{tabular}{lcc}
\hline $\begin{array}{l}\text { Regression on genetic } \\
\text { group coefficients }\end{array}$ & $\begin{array}{c}\text { Calf birth } \\
\text { weight }(\mathrm{kg})\end{array}$ & $\begin{array}{c}\text { Gestation } \\
\text { length }(\mathrm{d})\end{array}$ \\
\hline Direct genetic effects & $9.3 \pm 0.6^{*}$ & $-3.5 \pm 0.7^{*}$ \\
Maternal genetic effects & $1.7 \pm 0.5^{*}$ & $2.7 \pm 0.6^{*}$ \\
Direct heterosis & $\mathrm{NS}$ & $\mathrm{NS}$ \\
Maternal heterosis & $\mathrm{NS}$ & $\mathrm{NS}$ \\
\hline
\end{tabular}

${ }^{1}$ Based on $0 \%$ Holstein (JJ) moving to $100 \%$ Holstein (HH). ${ }^{*} P<0.01$.

\section{Calving Ease and Neonatal Calf Mortality}

Results of statistical analyses of calving ease (Table 5 ) and neonatal calf mortality (Table 6) are shown with their respective OR and corresponding CI. Because most calving difficulties occur in first parity, results are presented separately for first and later parities. Calves from primiparous cows were 1.95 times more likely to be assisted at birth in the current study. Olson et al. (2009) reported an OR of 2.30 for calves from primiparous cows. Johanson and Berger (2003) reported higher OR of 4.7 for calves requiring assistance when born to primiparous compared with multiparous Holstein dams.

Genetic group had no significant effect on calving ease in first or later parities. Sex was significant for calving ease $(P=0.04)$ in first parity, but not in later parities $(P=0.30)$. Female calves were $39 \%$ as likely as male calves to require assistance at calving for calves born to primiparous cows. Olson et al. (2009) found that female calves were $53.5 \%$ as likely as male calves to require assistance at calving.

Genetic group had no significant effect on neonatal calf mortality in first or later parities. Sex was not significant for explaining variation in neonatal calf mortality $(P=0.06)$ in first parity, but was significant in later parities $(P=0.04)$. Female calves had lower OR (0.32) for neonatal calf mortality than male calves born at second and later parities. The current study is consistent with the findings of Heins et al. (2006a) and Maltecca et al. (2006), in which male calves had higher OR for neonatal calf mortality than did female calves.
Results of regression analyses on genetic group components for calving ease and neonatal calf mortality are shown in Tables 7 and 8, respectively. The direct genetic effects, maternal genetic effects, direct heterosis, and maternal heterosis were not significant for calving ease in first parity or in second and later parities. However, Olson et al. (2009) found direct and maternal genetic effects to be significant and reported that $100 \% \mathrm{HH}$ calves were 134.9 times more likely to require assistance at calving than $100 \%$ JJ calves, and that calves born to Holstein dams were $22 \%$ as likely to require assistance at calving as those born to Jersey dams. Maternal heterosis was significant for neonatal calf mortality $(P$ $=0.03)$ in first parity but not in later parities $(P=$ $0.20)$, whereas direct genetic effects, maternal genetic effects, and direct heterosis did not have a significant effect on mortality in first or later parities. In the current study, maternal heterosis had a favorable effect on neonatal calf mortality in first parity. Neonatal calf mortality was $4.54 \%$ among calves (HX and JX) from crossbred dams, whereas mortality nearly doubled at $8.93 \%$ among calves (HH, JH, HJ, JJ) born to pure Holstein or Jersey cows. Although several other studies have reported significant differences among crosses, no significant differences in genetic group for calving ease and neonatal calf mortality were observed in the current study. However, numerical ranges in percentages of assisted calvings and neonatal calf mortality across genetic groups were substantial (Table 1) and may be biologically important. Furthermore, percentages of calving scores of 3 to 5 for primiparous genetic groups were as follows: $\mathrm{HH}(17.6 \%)$, HX (9.4\%), HJ (5.9\%), JH (8.6\%), JX (1.5\%), and JJ (5.0\%), but generally lower among multiparous genetic groups: $\mathrm{HH}(6.5 \%)$, HX (2.6\%), HJ (2.5\%), JH (1.0\%), JX (1.5\%), and JJ (1.1\%). Olson et al. (2009) found that purebred JJ calves were 5.7 and $7 \%$ as likely to require assistance as purebred $\mathrm{HH}$ and HJ crossbred calves, respectively. In contrast to the report of Olson et al. (2009), we found no evidence of a difference in calving ease between the reciprocal crosses (HJ vs. JH). Maltecca et al. (2006) reported that Holstein-sired HH calves were 1.24 times more likely than $75 \% \mathrm{HH}$ calves to require assistance at

Table 5. Odds ratios (OR) and corresponding CI for calving ease analysis ${ }^{1}$

\begin{tabular}{|c|c|c|c|c|c|c|}
\hline \multirow[b]{3}{*}{ Item } & \multicolumn{6}{|c|}{ Calving ease } \\
\hline & \multicolumn{3}{|c|}{ First parity } & \multicolumn{3}{|c|}{ Second and later parities } \\
\hline & $P$-value & OR & $\mathrm{CI}$ & $P$-value & OR & CI \\
\hline Genetic group & NS & & & NS & & \\
\hline Sex (female vs. male) & 0.04 & 0.39 & $0.16-0.97$ & 0.30 & 1.42 & $0.73-2.77$ \\
\hline
\end{tabular}


Table 6. Odds ratios (OR) and corresponding CI for neonatal calf mortality analysis ${ }^{1}$

\begin{tabular}{|c|c|c|c|c|c|c|}
\hline \multirow[b]{3}{*}{ Item } & \multicolumn{6}{|c|}{ Neonatal calf mortality } \\
\hline & \multicolumn{3}{|c|}{ First parity } & \multicolumn{3}{|c|}{ Second and later parities } \\
\hline & $P$-value & OR & CI & $P$-value & OR & $\mathrm{CI}$ \\
\hline Genetic group & NS & & & NS & & \\
\hline Sex (female vs. male) & 0.06 & 0.17 & $0.03-1.13$ & 0.04 & 0.32 & $0.10-0.99$ \\
\hline
\end{tabular}

${ }^{1}$ Odds ratios $<1$ for mortality $=$ fewer calves born dead or died within $48 \mathrm{~h}$ of birth.

birth when born to Holstein dams. Heins et al. (2006a) found that crossbred calves had lower calving difficulty than purebred Holstein calves. Olson et al. (2009) reported that, among reciprocal crossbreds, HJ were 3.61 times more likely to be stillborn than JH calves but that effect was not observed in the current study.

The percentage of assisted calvings in the current study was $7.8 \%$ across all observations, with $11.3 \%$ among first-parity dams and $5.9 \%$ among multiparous dams. Those percentages are lower for assisted calvings than the respective $11.2 \%$ across all observations, including $18.1 \%$ among first-parity dams and $8.2 \%$ among multiparous dams calculated from the report of Olson et al. (2009), who categorized calving ease scores of 1 and 2 as unassisted. If calving ease scores of 1 and 2 were included as unassisted in the current study, the overall percentage of assisted calvings (scores of 3, 4, and 5 ) would have been $4.2 \%$. Among $\mathrm{HH}$ in first parity, $17.6 \%$ of assisted births in the current study had calving scores of 3,4 , and 5 , which is similar to the $19.0 \%$ reported by Dematawewa and Berger (1997) but less than the $36.0 \%$ reported by Olson et al. (2009). Considering scores of 4 and 5 , the current study had $9.8 \%$ difficult births, whereas Dematawewa and Berger (1997) reported $7.45 \%$, Heins et al. (2006a) reported $16.4 \%$, and Heins et al. (2010) reported $14.9 \%$ difficult births (scores $=4$ and 5) among first-parity Holsteins. Bjelland et al. (2011) noted that first-parity crossbred cows with $75 \%$ Holstein genetics (25\% Jersey) mated to $100 \%$ Holstein sires had $11.2 \%$ assisted calvings (scores $=3$ to 5 ) compared with $3.7 \%$ for a control group of first-parity Holstein cows mated to Holstein sires. However, the rate of difficult births among first-parity pure Holsteins in the study of Bjelland et al. (2011) was low compared with that in the current study and with other reports (Dematawewa and Berger, 1997; Maltecca et al., 2006; Heins et al., 2006a, 2010; Olson et al., 2009). The low to moderate levels of difficult births in the current study may be due in part to use of calving ease Holstein sires for breeding heifers and may also be affected by the pasture-based system, in which cows have more activity and exercise based on lower BCS among pastured cows (Washburn et al., 2002).

The percentage of stillbirth in the current study was $6.6 \%$ across all observations, with $9.6 \%$ among firstparity dams and $5.1 \%$ among multiparous dams. Those percentages are lower than the respective $8.6 \%$ across all observations, with $13.7 \%$ among first-parity dams and $6.4 \%$ among multiparous dams calculated from the report of Olson et al. (2009). The current study had $15.7 \%$ neonatal calf mortality for $\mathrm{HH}$ calves from primiparous dams, whereas Olson et al. (2009) reported 20.9\%, Heins et al. (2006a) reported 15.1\%, and Heins et al. (2010) reported $16.9 \%$ neonatal calf deaths among $\mathrm{HH}$ calves born to primiparous cows.

Overall, assisted calvings and neonatal calf mortality in the current study were 7.8 and $6.6 \%$ respectively, similar to those reported in the study by Berry et al. (2007), in which rates of calving ease and neonatal calf mortality were 7 and $6 \%$, respectively, for a pasturebased dairy system in New Zealand (data from 1986 to 2000) that included both Holstein and Jersey genetics.

Table 7. Odds ratios (OR) and associated CI of regression on genetic group for calving ease

\begin{tabular}{|c|c|c|c|c|c|c|}
\hline \multirow{3}{*}{$\begin{array}{l}\text { Regression on genetic } \\
\text { group coefficients }^{1}\end{array}$} & \multicolumn{6}{|c|}{ Calving ease } \\
\hline & \multicolumn{3}{|c|}{ First parity } & \multicolumn{3}{|c|}{ Second and later parities } \\
\hline & $P$-value & OR & CI & $P$-value & OR & $\mathrm{CI}$ \\
\hline Direct genetic effects & 0.41 & 2.0 & $0.30-12.79$ & 0.64 & 1.41 & $0.33-6.13$ \\
\hline Maternal genetic effects & 0.49 & 0.6 & $0.12-3.14$ & 0.52 & 1.45 & $0.46-4.58$ \\
\hline Direct heterosis & 0.64 & 0.76 & $0.19-2.98$ & 0.29 & 1.76 & $0.62-5.03$ \\
\hline Maternal heterosis & 0.88 & 1.07 & $0.35-3.33$ & 0.20 & 1.70 & $0.76-3.77$ \\
\hline
\end{tabular}

${ }^{1}$ Based on $0 \%$ Holstein (JJ) moving to $100 \%$ Holstein (HH). 
Table 8. Odds ratios (OR) and associated CI of regression on genetic group for neonatal calf mortality

\begin{tabular}{|c|c|c|c|c|c|c|}
\hline \multirow{3}{*}{$\begin{array}{l}\text { Regression on genetic } \\
\text { group coefficients }{ }^{1}\end{array}$} & \multicolumn{6}{|c|}{ Neonatal calf mortality } \\
\hline & \multicolumn{3}{|c|}{ First parity } & \multicolumn{3}{|c|}{ Second and later parities } \\
\hline & $P$-value & OR & $\mathrm{CI}$ & $P$-value & OR & CI \\
\hline Direct genetic effects & 0.66 & 0.58 & $0.03-10.74$ & 0.11 & 0.05 & $0.001-2.10$ \\
\hline Maternal genetic effects & 0.89 & 0.89 & $0.10-7.43$ & 0.11 & 20.72 & $0.48-892.41$ \\
\hline Direct heterosis & 0.80 & 1.19 & $0.24-5.86$ & 0.12 & 0.19 & $0.02-1.56$ \\
\hline Maternal heterosis & 0.03 & $0.05^{2}$ & $0.003-0.74$ & 0.20 & 0.36 & $0.07-1.76$ \\
\hline
\end{tabular}

${ }^{1}$ Based on $0 \%$ Holstein (JJ) moving to $100 \%$ Holstein (HH).

${ }^{2}$ Odds ratio $<1$ for mortality $=$ fewer calves born dead or died within $48 \mathrm{~h}$ of birth.

Data from 1972 to 1985 in a mixed herd of Danish Red, Finnish Ayrshire, Holstein, and various crosses were reported by Sørensen et al. (2008), who found $10.8 \%$ assisted calvings (scores of 3 to 5 ) and $8.0 \%$ neonatal calf mortality for calves from first-parity cows and $2.9 \%$ calving ease and $4.4 \%$ neonatal calf mortality among calves born to older cows.

\section{CONCLUSIONS}

The percentages of difficult births among primiparous cows in the present study were generally similar to or less than those reported in other studies. Reduced neonatal calf mortality among calves born to crossbred dams in first parity is a potential advantage for producers considering the use of crossbreeding in a pasture-based system. Use of Holstein and Jersey genetics in a planned 2-breed crossbreeding program in a pasture-based dairy system can be accomplished without adverse effects on calf mortality and calving ease compared with the use of pure breeds. Use of calving ease Holstein sires is recommended for breeding heifers. Further research should be focused on collecting data targeted to identify differences in calving ease and neonatal calf mortality among various crossbreds in differing management systems.

\section{ACKNOWLEDGMENTS}

The authors acknowledge the late Ben McDaniel (North Carolina State University, Raleigh) for the crossbreeding design and thank former undergraduate students Katie Jackson and David Latta (North Carolina State University, Raleigh) and Claudia Sevillano (National Agrarian University, Lima, Peru), who helped with data collection and summary. We also acknowledge Windy Wainwright, Andrew Meier, and other staff at CEFS (Goldsboro, NC) for their hard work in data recording.

\section{REFERENCES}

Berry, D. P., J. M. Lee, K. A. Macdonald, and J. R. Roche. 2007. Body condition score and body weight effects on dystocia and stillbirths and consequent effects on postcalving performance. J. Dairy Sci. 90:4201-4211.

Bjelland, D. W., K. A. Weigel, P. C. Hoffman, N. M. Esser, W. K. Coblentz, and T. J. Halbach. 2011. Production, reproduction, health, and growth traits in backcross Holstein $\times$ Jersey cows and their Holstein contemporaries. J. Dairy Sci. 94:5194-5203.

Dematawewa, C. M. B., and P. J. Berger. 1997. Effect of dystocia on yield, fertility, and cow losses and an economic evaluation of dystocia scores for Holsteins. J. Dairy Sci. 80:754-761.

Heins, B. J., L. B. Hansen, A. R. Hazel, A. J. Seykora, D. G. Johnson, and J. G. Linn. 2010. Birth traits of pure Holstein calves versus Montbeliarde-sired crossbred calves. J. Dairy Sci. 93:2293-2299.

Heins, B. J., L. B. Hansen, and A. J. Seykora. 2006a. Calving difficulty and stillbirths of pure Holsteins versus crossbreds of Holstein with Normande, Montbeliarde, and Scandinavian Red. J. Dairy Sci. $89: 2805-2810$.

Heins, B. J., L. B. Hansen, and A. J. Seykora. 2006b. Production of pure Holsteins versus crossbreds of Holstein with Normande, Montbeliarde, and Scandinavian Red. J. Dairy Sci. 89:2799-2804.

Heins, B. J., L. B. Hansen, A. J. Seykora, D. G. Johnson, J. G. Linn, J. E. Romano, and A. R. Hazel. 2008. Crossbreds of Jersey $x$ Holstein compared to pure Holsteins for production, fertility, and body and udder measurements during first lactation. J. Dairy Sci. 91:1270-1278.

Heins, B. J., A. J. Seykora, L. B. Hansen, J. G. Linn, and W. P. Hansen. 2003. Effect of mating Holstein females to Holstein versus Jersey AI sires on fertility, dystocia, calf weight, and retained placenta. J. Dairy Sci. 86(Suppl. 1):130. (Abstr.)

Johanson, J. M., and P. J. Berger. 2003. Birth weight as a predictor of calving ease and perinatal mortality in Holstein cattle. J. Dairy Sci. 86:3745-3755.

Maltecca, C., H. Khatib, V. R. Schutzkus, P. C. Hoffman, and K. A. Weigel. 2006. Changes in conception rate, calving performance, and calf health and survival from the use of crossbred Jersey $x$ Holstein sires as mates for Holstein dams. J. Dairy Sci. 89:27472754 .

Olson, K. M., B. G. Cassell, A. J. McAllister, and S. P. Washburn. 2009. Dystocia, stillbirth, gestation length, and birth weight in Holstein, Jersey, and reciprocal crosses from a planned experiment. J. Dairy Sci. 92:6167-6175.

Prendiville, R., K. M. Pierce, and F. Buckley. 2010. A comparison between Holstein-Friesian and Jersey dairy cows and their $\mathrm{F}_{1}$ cross with regard to milk yield, somatic cell score, mastitis, and milking characteristics under grazing conditions. J. Dairy Sci. 93:27412750 .

Robison, O. W., B. T. McDaniel, and E. J. Rincon. 1981. Estimation of direct and maternal additive and heterotic effects from crossbreeding experiments in animals. J. Anim. Sci. 52:44-50. 
Silva, H. M., C. J. Wilcox, W. Thatcher, R. B. Becker, and D. Morse. 1992. Factors affecting days open, gestation length, and calving interval in Florida dairy cattle. J. Dairy Sci. 75:288-293.

Sørensen, M. K., E. Norberg, J. Pedersen, and L. G. Christensen. 2008. Invited review: Crossbreeding in dairy cattle: A Danish perspective. J. Dairy Sci. 91:4116-4128.

Touchberry, R. W. 1992. Crossbreeding effects in dairy cattle: The Illinois experiment, 1949 to 1969. J. Dairy Sci. 75:640-667.
Washburn, S. P., S. L. White, J. T. Green Jr., and G. A. Benson. 2002. Reproduction, mastitis, and body condition of seasonally calved Holstein and Jersey cows in confinement or pasture systems. J. Dairy Sci. 85:105-111.

Weigel, K. A., and K. A. Barlass. 2003. Results of a producer survey regarding crossbreeding on US dairy farms. J. Dairy Sci. $86: 4148-4154$ 